\title{
LEVANTAMENTO ARQUITETÔNICO DAS EDIFICAÇÕES RELIGIOSAS NAS SUPERQUADRAS DE BRASÍLIA
}

\section{LEVANTAMIENTO ARQUITECTÔNICO DE EDIFICIOS RELIGIOSOS EN LAS SUPERQUADRAS DE BRASÍLIA}

\section{ARCHITECTURAL SURVEY OF RELIGIOUS BUILDINGS IN THE "SUPERQUADRAS" OF BRASÍLIA}

\author{
AMIZO, ISADORA BANDUCCI
}

Doutoranda no Programa de pós-graduação em Arquitetura e Urbanismo da Universidade de Brasília, Docente do Curso de Arquitetura e Urbanismo da UNIPBrasília. E-mail: isadorabanducci@gmail.com

\section{ANCHIETA, DANIEL GUTENBERG ELOI}

Mestrando no Programa de pós-graduação em Arquitetura e Urbanismo da Universidade de Brasília. E-mail: danielgutenberg@hotmail.com

\section{SAMPAIO, FLORA SOPHIA FAGANELLO}

Bacharel no Curso de Arquitetura e Urbanismo da UNIP-Brasília. E-mail: flora.sophia@hotmail.com

\section{RESUMO}

A pesquisa apresentada neste artigo consiste em um levantamento arquitetônico das edificações religiosas localizadas nas superquadras do Plano Piloto de BrasíliaDF. A proposta partiu do reconhecimento prévio da ausência de informações a respeito dessas edificações nos estudos sobre a arquitetura da capital brasileira e, portanto, da necessidade de investigação e divulgação dessas edificações. A pesquisa se desenvolveu como uma catalogação, apoiada em uma abordagem de cunho descritivo e analítico. Objetivou-se, além do levantamento e da documentação, analisar os princípios e condicionantes que regem as formas e linguagens arquitetônicas dessas edificações. Para tanto, foram feitos levantamentos in loco, com registros fotográficos e anotações sistematizados por meio de fichas, além de consulta aos registros e aos responsáveis pela administração das instituições. Foi mapeado o total de vinte e sete edificações, com datas de construção entre 1958 (período da construção da cidade) até 2007. Os dados registrados abrangem: a identificação da edificação e sua localização; 0 ano de construção; a religião a qual está vinculada; o uso para o qual foi projetada; os responsáveis pelo projeto; reformas significativas; e uma breve descrição formal. Entende-se que esse trabalho poderá contribuir com a construção do conhecimento de uma parte da história da arquitetura de Brasília ainda pouco explorada.

PALAVRAS-CHAVE: levantamento arquitetônico; edificações religiosas; brasília.

\section{RESUMEN}

La investigación presentada en este artículo consiste en un levantamiento arquitectónico de edificios religiosos ubicados en las Superquadras del Plano Piloto de Brasilia-DF. La propuesta partió del reconocimiento previo de la falta de información sobre esta tipología en los estudios sobre la arquitectura de Brasilia y, por tanto, la necesidad de investigación y difusión de estos edificios. La investigación se desarrolló en forma de catálogo, sustentada en un enfoque descriptivo y analítico. Además de lo levantamiento y documentación, el objetivo fue analizar los principios y condiciones que rigen las formas arquitectónicas y los lenguajes de los edificios. Para ello, se realizaron encuestas in situ, con registros fotográficos y apuntes, sistematizados mediante archivos, y consultas con los registros y los responsables de la administración de las instituciones. Se mapearon un total de veintisiete edificios, con fechas de construcción entre 1958 (período de construcción de la ciudad) hasta 2007. Los datos registrados incluyen la identificación del edificio y su ubicación; el año de construcción; la religión a la que está vinculado; el uso para el que fue diseñado; los responsables del proyecto; reformas significativas; y una breve descripción formal. Se cree, por tanto, que este trabajo puede contribuir a la construcción del conocimiento de una parte de la historia de la arquitectura en Brasilia que aún está poco explorada.

PALABRAS CLAVES: levantaminento arquitectónico; edificios religiosos; brasilia.

\section{ABSTRACT}

The research presented in this article consists of an architectural survey of religious buildings located in the Superquadras of Brasilia-DF. The proposal was based on the previous recognition of the lack of information on this typology in studies on the architecture of Brasilia and, therefore, on the need for investigation and dissemination of these buildings. The research was developed in the form of a catalog, supported by a descriptive and analytical approach. In addition to the research, the objective was to analyze the principles and conditions that govern the architectural forms and languages of these buildings. For this, surveys were carried out on the spot, with photographic records and notes, systematized by means of files, and consultations with the registry offices and those responsible for the administration of the institutions. 27 buildings were mapped, with construction dates between 1958 (city construction period) and 2007. The recorded data include the building's identification and its location; the year of construction; the religion to which it is linked; the use for which it was designed; those responsible for the project; significant reforms; and a brief formal description. It is believed, therefore, that this work can contribute to the construction of knowledge of a part of the history of Brasilia's architecture that is still little explored.

KEYWORDS: architectural survey; religious buildings; brasilia. 


\section{INTRODUÇÃO}

A pesquisa apresentada consiste em um levantamento arquitetônico das edificações religiosas localizadas nas superquadras do Plano Piloto, em Brasília (Distrito Federal, Brasil). É fruto de um trabalho desenvolvido ao longo do processo de Iniciação Científica, que teve início com o interesse em complementar os estudos de história da arquitetura desenvolvidos em sala de aula no curso de graduação em Arquitetura e Urbanismo e nas atividades de monitoria de ensino. Partiu, ainda, do reconhecimento prévio de que, embora o conjunto arquitetônico de Brasília seja objeto recorrente de estudos, algumas lacunas ainda são identificadas para uma investigação mais cuidadosa.

No Plano Piloto, núcleo central dessa cidade, identificam-se algumas edificações ainda pouco registradas e divulgadas, como é o caso das edificações religiosas - categoria aqui tratada -, o que instiga um reconhecimento mais completo e sistematizado delas. Assim sendo, buscou-se realizar o mapeamento e 0 levantamento dos dados, características e histórias dessas edificações, localizadas mais especificamente nas superquadras e entrequadras (área entre duas superquadras) das Asas Norte e Sul. O objetivo era, não apenas reconhecer e descrever tais edificações, mas, também, identificar possíveis princípios e condicionantes que regem suas formas e linguagens arquitetônicas.

A pesquisa foi metodologicamente desenvolvida como uma catalogação, apoiando-se em uma abordagem de cunho descritivo e analítico. Para que os objetivos fossem atingidos foram necessários os levantamentos in loco, com registros fotográficos e anotações sistematizados por meio de fichas, ao que somou-se a consulta aos responsáveis pela administração das respectivas instituições e a seus registros históricos. 0 trabalho foi realizado por dois estudantes, sendo um responsável pelo levantamento das superquadras na Asa Norte e a outra das superquadras na Asa Sul, ambos orientados pela professora com quem dividem a autoria desse texto.

$\mathrm{Na}$ primeira parte do artigo é feita a contextualização das superquadras, locais onde se inserem as edificações estudadas, por meio da descrição de sua configuração e da aplicação desse conceito no projeto de Brasília. Na sequência, é apresentado o processo de levantamento e sistematização das informações coletadas, assim como os desafios enfrentados. A partir de então, apresentam-se os resultados obtidos e algumas análises sobre eles.

Entende-se que esse trabalho poderá contribuir com a documentação dessas edificações, oferecendo dados preliminares sobre objetos ainda pouco explorados da história da arquitetura de Brasília. Ainda que parcial e modestamente, instiga-se, aqui, uma reflexão sobre a produção arquitetônica dessa cidade desde a sua construção.

\section{DESENVOLVIMENTO}

A concepção urbanística de Brasília advém do projeto idealizado pelo arquiteto e urbanista Lucio Costa (1902-1998), vencedor do Concurso Nacional para o Plano Piloto da Nova Capital do Brasil, realizado em 1957. Traz referências do Movimento Moderno, no que se refere às soluções rodoviaristas para a circulação urbana e à setorização rigorosa das atividades (FICHER, PALAZZO, 2005), e se estrutura em quatro escalas: monumental, bucólica, gregária e residencial.

As superquadras fazem parte dos Setores Residenciais, projetados para acomodar os funcionários transferidos da antiga capital, já previstos pelo edital do concurso. Conforme o projeto, essas deveriam receber os blocos residenciais, construídos sobre pilotis, adotando gabaritos iguais e liberando o térreo para a circulação e o acesso de todos. Dentro delas, os pedestres teriam acesso à escola primária e aos serviços e comércios internos, sem interferência do automóvel. A cada quatro quadras, estariam os demais equipamentos, como as escolas secundárias, a igreja, o cinema etc. (TAVARES, 2014) (Figura 1).

Lucio Costa as descreve da seguinte maneira no relatório do projeto:

Entaladas entre essa via de serviço (W3) e as vias do eixo rodoviário, intercalaram-se então largas e extensas faixas com acesso alternado, ora por uma, ora por outra, e onde se localizaram a igreja, as escolas secundárias, o cinema e o varejo do bairro, disposto conforme sua classe ou natureza (COSTA, 2014 [1957], s. p., grifo nosso).

Essa junção das quatro quadras, equipadas para alimentar as atividades cotidianas dos moradores teria sido uma reformulação do conceito de Unidade de Vizinhança, originalmente proposto pelo planejador norte-americano Clarence Perry (1872-1944), nos anos 1920, como módulo agenciador da trama urbana (FERREIRA; GOROVITZ, 2020). Consiste em uma conjugação de unidades residenciais em escala de bairro, tendo a escola primária como equipamento principal. 
Figura 1. Exemplo de Unidade de Vizinhança de Brasília, concebida por Lucio Costa,

com as superquadras e entrequadras em destaque.

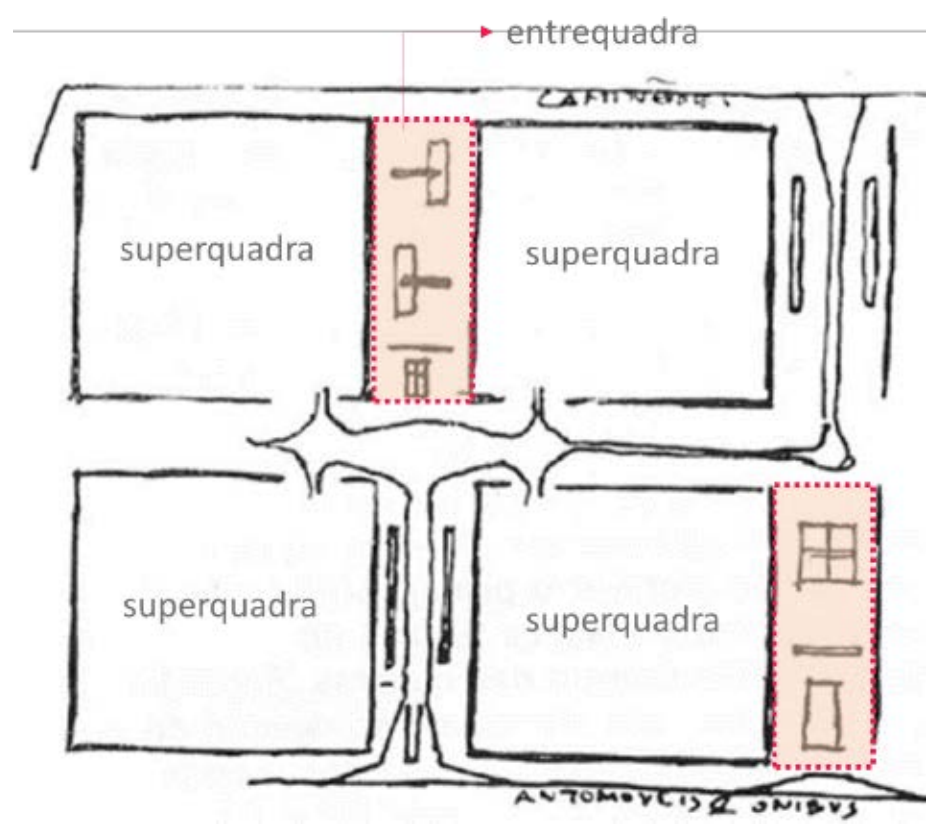

Fonte: FERREIRA, M. M.; GOROVITZ, M., 2020. Modificado pelos autores.

Dentre as que foram construídas em Brasília, quase todas se apresentam atualmente incompletas, no que diz respeito à totalidade desses equipamentos previstos, com exceção do conjunto das Superquadras 107 , 108, 307 e 308 (na Asa Sul). Essa última é chamada quadra modelo, devido não só aos equipamentos presentes, mas também pelos projetos arquitetônicos e paisagísticos que recebeu. Nela se destaca a arquitetura da Igreja Nossa Senhora de Fátima, também conhecida como Igrejinha, projetada pelo arquiteto Oscar Niemeyer (1907-2012) e inaugurada em 1958.

As igrejas fazem, portanto, parte do conjunto de equipamentos previstos na composição das superquadras. $\mathrm{E}$, embora muitos desses conjuntos não se encontrem completos, a presença dessas instituições é recorrente nos seus interiores ou nas chamadas entrequadras - onde, geralmente se localizam os lotes ${ }^{1}$ destinados a instituições e áreas de lazer. São edificações religiosas de diversas tradições e crenças, com formas e linguagens arquitetônicas distintas, construídas ao longo dos mais de 60 anos de história da cidade.

Vale lembrar, também, que o primeiro Código de Obras e Edificações de Brasília, datado de 1967, definiu que a construção de templos seria permitida apenas nos lotes com tal destinação na Zona Residencial superquadras -, ou nos Setores de Grandes Áreas, o que reforça, portanto, o estímulo a sua presença nesses locais, somando-se às intenções do projeto como Unidade de Vizinhança. Jayme Zettel (1931 -), chefe da Divisão de Urbanismo da Novacap ${ }^{2}$ durante a construção de Brasília, comentou sobre o local de implantação das igrejas, em entrevista concedida em 2002:

\begin{abstract}
O projeto de distribuição das igrejas pelas quadras foi pensado privilegiando as Igrejas Católicas. O Brasil é um país católico, então essas igrejas foram dispostas pelas Superquadras. Então, surgiram outras religiões reclamando seus direitos (...), nós tivemos que achar uma alternativa para responder a essa demanda e criamos o Setor de Grandes Áreas acomodando as escolas particulares e essas seitas, essas outras igrejas que tinham uma pressão muito grande no governo (FERREIRA; GOROVITZ, 2020, p. 113)
\end{abstract}

Atualmente, porém, as edificações religiosas encontradas nas superquadras não estão vinculadas apenas à religião católica e, além delas, também há templos adaptados em edificações já existentes ao longo das vias de comércio. Esses últimos, no entanto, apresentam pouca expressão arquitetônica e, em muitos casos, são pouco visíveis externamente, já que se situam no interior dos blocos comerciais, adaptando-se às formas predeterminadas desses blocos. A decisão por descartá-las do levantamento aqui apresentado, assim como as dos Setores de Grandes Áreas, deve-se, além da necessidade de recorte para viabilização da pesquisa em tempo hábil, ao interesse em estudar as variações (em seus partidos e linguagens) existentes dentro de um contexto morfológico e conceitual específico. Se por um lado, o recorte limita a 
análise de toda a arquitetura religiosa da cidade, por outro, valoriza o estudo dos edifícios que compõem o conjunto da superquadra, elemento expressivo e fundamental da concepção urbanística de Brasília.

Quanto à forma dos edifícios a serem implantados nas superquadras, Lucio Costa listou recomendações, como sugestão para o Código de Obras de Brasília, em texto de 1960. Segundo ele:

3.2. - O partido deve ser claro, e as formas devem ser simples; deve haver sobriedade no emprego de elementos e no de materiais diferentes; 3.3 - o projeto não pode ser: complicado, extravagante, pretensioso ou rebuscado; 4.1. - As formas usadas nas estruturas monumentais não podem ser transpostas para a escala residencial (COSTA, 1960, apud ROCHA, 2011).

No texto do arquiteto não fica claro se essas recomendações se restringem aos blocos residenciais ou se abrangem todos os edifícios das superquadras, incluindo os equipamentos comunitários, como as edificações religiosas. Porém, ainda que não tratem especificamente delas, as sugestões lançadas dão indícios da expectativa de Costa pela definição de uma linguagem para o conjunto, alinhada aos princípios da arquitetura moderna, compartilhados nos projetos das demais edificações iniciais da cidade e à preocupação em respeitar os diferentes papéis de cada escala (residencial e monumental).

\section{Levantamento e organização dos dados}

Um dos desafios encontrados no trabalho se deu já no início do processo de identificação e mapeamento das edificações, quanto ao recorte dos tipos de instituições religiosas que seriam consideradas. Entre as identificadas, constava uma variedade de crenças, que resultam em tipologias muito distintas de edificações, como templos, sedes de seitas, filosofias, doutrinas e lojas maçônicas. Foi, portanto, a partir da impossibilidade de abranger todas em um só termo, que se encaminhou a decisão por denominá-las de modo mais amplo e simplificado como "edificações religiosas", mesmo que nem todas se identifiquem como religiões, de fato. O termo "sacro" não foi utilizado por se entender que este se associa ainda mais ao sentido de veneração e dedicação a divindades, não abrangendo, portanto, vários dos casos em questão.

Houve, ainda, dificuldade em encontrar na bibliografia sobre a arquitetura da cidade informações específicas a respeito das edificações mapeadas, o que exigiu o contato com os responsáveis pela administração de cada uma, em busca de informações mais completas. Ainda assim, não foram encontrados todos os dados precisos a respeito dos autores e data dos projetos, o que confirma a suposição da carência de registros sobre eles. Todas as informações coletadas no primeiro momento foram organizadas em fichas catalográficas de cada edificação, contendo: a identificação da edificação e sua localização; ano de construção; religião a qual está vinculada; uso para o qual foi projetada; arquiteto(a) responsável; reformas significativas; e uma breve descrição formal ${ }^{3}$. A escolha desses itens se deve ao intuito de identificar as condicionantes que conduziram a elaboração dos partidos arquitetônicos.

As análises que se seguiram tomaram como base as informações encontradas por meio do levantamento, apoiadas em bibliografia pertinente. Elas se concentraram, sobretudo, nos exteriores das edificações, devido à dificuldade de acesso às plantas e demais dados dos projetos, embora também tenham sido acessadas internamente e redesenhadas na forma de croquis para estudo mais completo ${ }^{4}$. As características arquitetônicas das edificações foram relacionadas com o período, o (a) autor(a) do projeto e contexto em que foram projetadas, o pode ajudar a entender se há convergência de linguagens e expressões entre elas.

Durante a pesquisa foi mapeado o total de vinte e sete edificações religiosas (Tabela 1 e Figuras 2 e 3). Catorze delas estão localizadas nas Superquadras Sul e as outras trezes estão localizadas nas Superquadras Norte ${ }^{5}$. Nas duas Asas, as edificações estão localizadas nas faixas 300 e $400^{6}$, em posições relativamente diferentes com relação às quadras, tendo em vista os diferentes desenhos que essas parcelas apresentam, quando se comparam as duas faixas. Os limites que definem as Superquadras 300 são mais bem definidos, embora não haja barreiras verticais (como cercas e muros).

Portanto, é mais fácil identificar que as edificações religiosas, nelas situadas, encontram-se, necessariamente nas entrequadras, alinhadas com as vias de comércio, recebendo maior destaque e visibilidade. Já na faixa das 400 , esses limites são mais diluídos. Nelas, a implantação das edificações religiosas varia entre as entrequadras e o próprio perímetro interno da superquadra (Figuras 4 e 5). Tal situação ocorre igualmente em ambas as Asas. 
Amizo, I. B; Anchieta, D. G. E; Sampaio, F. S. F.

Tabela 1. Dados básicos sobre as edificações religiosas levantadas nas Superquadras Sul e Norte

\begin{tabular}{|c|c|c|c|}
\hline \multicolumn{4}{|c|}{ Edificações religiosas nas Superquadras Sul } \\
\hline Nome da instituição & Localização & Ano de construção & Autor(a) do projeto \\
\hline 1. Igreja Nossa Senhora de Fátima & EQS 307/308 & 1958 & Oscar Niemeyer \\
\hline 2. Igreja Episcopal Anglicana & EQS 309/310 & 1960 & Glauco Campelo \\
\hline 3. Igreja de Cristo de Brasília & EQS 305/306 & 1961 & Não Identificado \\
\hline 4. Templo Shin Budista Terra Pura & EQS 315/316 & 1964 & Jihei Noda \\
\hline $\begin{array}{l}\text { 5. Comunidade Evangélica de Confissão } \\
\text { Luterana de Brasília }\end{array}$ & SQS 406 & 1969 & Del Nero \\
\hline 6. Igreja de Deus em Brasília & SQS 409 & 1969 & Alcina Ferreira Neves \\
\hline 7. Templo Seicho-No le & SQS 404 & 1977 & Não Identificado \\
\hline 8. Igreja Presbiteriana de Brasília & EQS 313/314 & 1978 & Jair Rosa e Rubens Branquin \\
\hline 9. Igreja Cristã Maranata & SQS 414 & 1980 & Edilson Rocha Dias \\
\hline $\begin{array}{l}\text { 10. Paroquia Nossa Senhora de } \\
\text { Guadalupe }\end{array}$ & EQS 311/312 & 1999 & $\begin{array}{l}\text { Vicente Paulo Lima e } \\
\text { Francisco Salgado }\end{array}$ \\
\hline 11. Paróquia São Camillo de Lellis & EQS 303/304 & Não Identificado & Não identificado \\
\hline 12. Federação Espírita & SQS 408 & Não identificado & Não identificado \\
\hline 13. Igreja do Nazareno & SQS 411 & Não identificado & Não identificado \\
\hline 14. Igreja Congregacional de Brasília & SQS 416 & Não identificado & Não identificado \\
\hline \multicolumn{4}{|c|}{ Edificações religiosas nas Superquadras Norte } \\
\hline Nome & Localização & Ano de construção & Autor(a) do projeto \\
\hline 15. Igreja Presbiteriana da Alvorada & SQN 410 & 1968 & Jair Fernandes Rosa \\
\hline 16. Grande Oriente do Distrito Federal & SQN 415 & 1971 & Não identificado \\
\hline 17. Igreja Messiânica Mundial do Brasil & EQN 315/316 & 1979 & Raul Molina \\
\hline 18. Igreja Cristã Evangélica de Brasília & EQN 309/310 & 1981 & Ariomar da Luz Nogueira \\
\hline 19. Igreja Nova Vida de Brasília & SQN 412 & 1996 & Maria Emilia L. Yamada \\
\hline $\begin{array}{l}\text { 20. Paróquia Militar de São Miguel } \\
\text { Arcanjo e Santo Expedito }\end{array}$ & EQN 303/304 & 1997 & Não identificado \\
\hline $\begin{array}{l}\text { 21. Paróquia Nossa Senhora da } \\
\text { Esperança }\end{array}$ & EQN 307/308 & 1999 & Jefferson Nerasti \\
\hline 22. Igreja Batista Capital & SQN 407 & $\begin{array}{l}\text { Década de } 1990 \\
\text { (sem ano preciso) }\end{array}$ & Não identificado \\
\hline 23. Capela da Divina Misericórdia & EQN 311/312 & 2007 & Elídia Maria Torres \\
\hline 24. Primeira Igreja Batista da Asa Norte & EQN 313/314 & Não identificado & Não identificado \\
\hline 25. Associação Cultural Israelita Brasília & EQN 305/306 & Não identificado & Não identificado \\
\hline 26. Igreja Metodista & SQN 406 & Não identificado & Não identificado \\
\hline 27. Igreja Luterana & SQN 404 & Não identificado & Não identificado \\
\hline
\end{tabular}


Figura 2. Mapa de localização dos templos nas Superquadras Sul
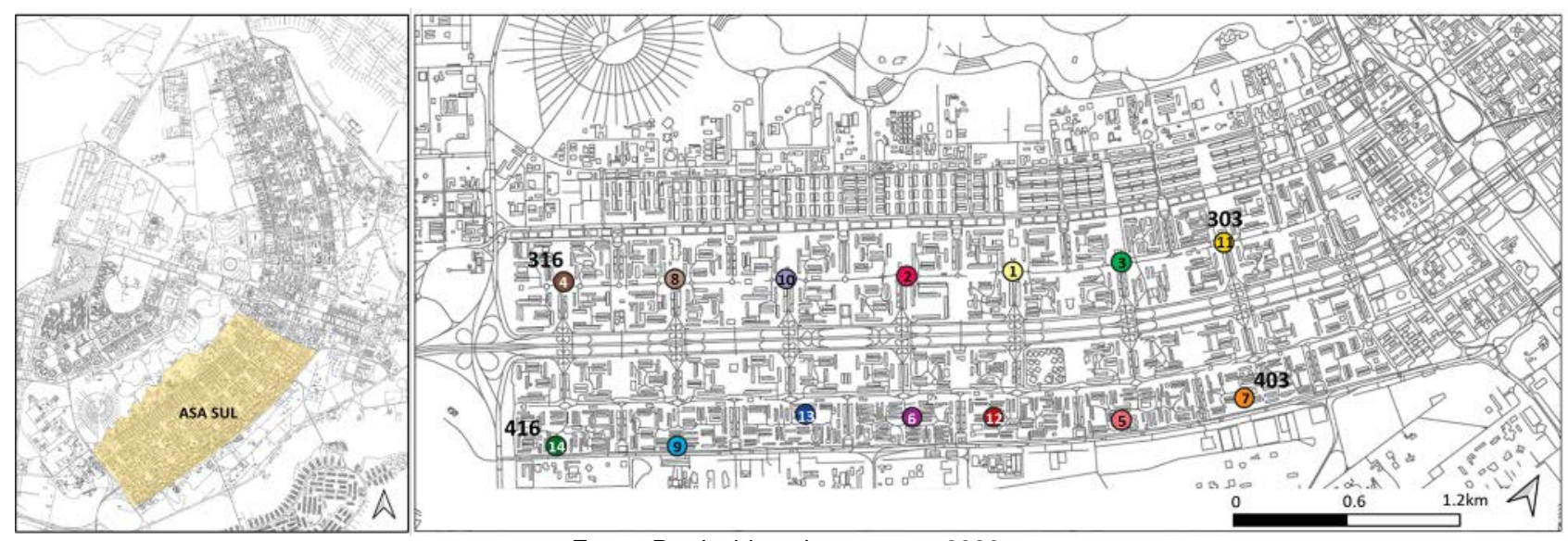

Fonte: Produzido pelos autores, 2020.

Figura 3. Mapa de localização dos templos nas Superquadras Norte

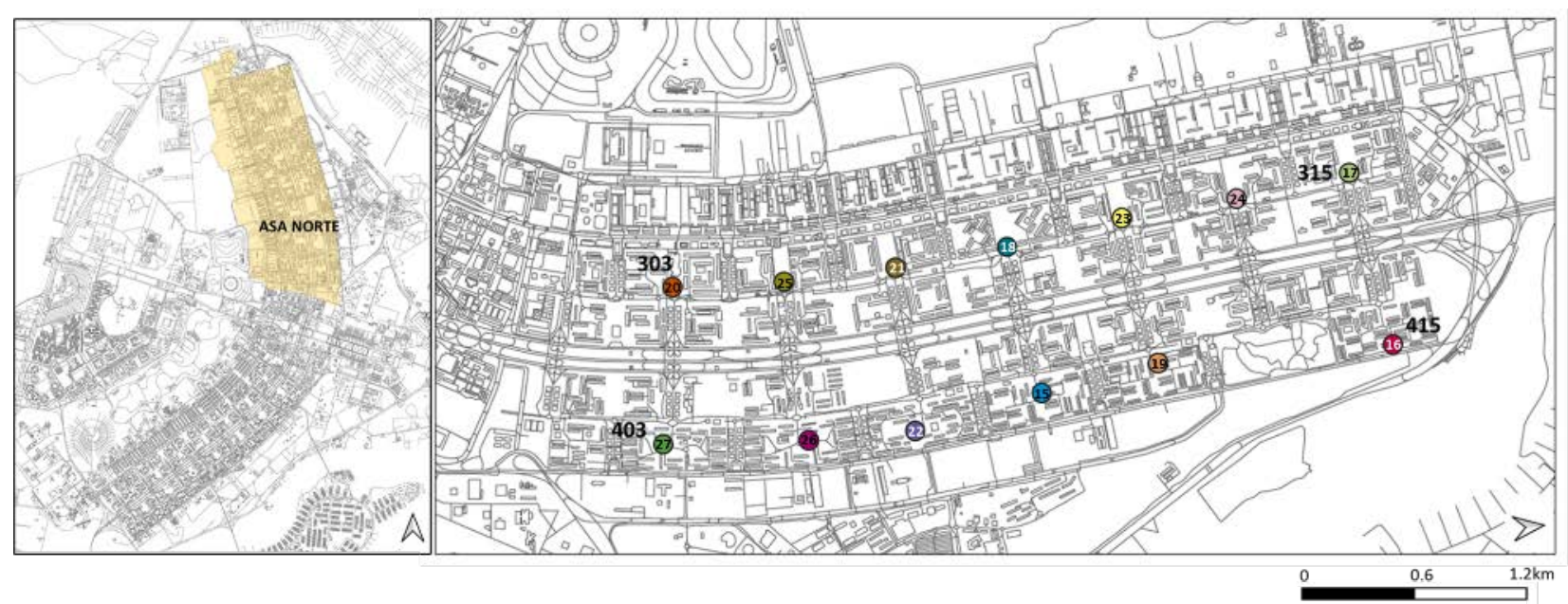

Fonte: Produzido pelos autores, 2020.

Figura 4. Localização do Templo Shin Budista na Entrequadra 315/316 Sul

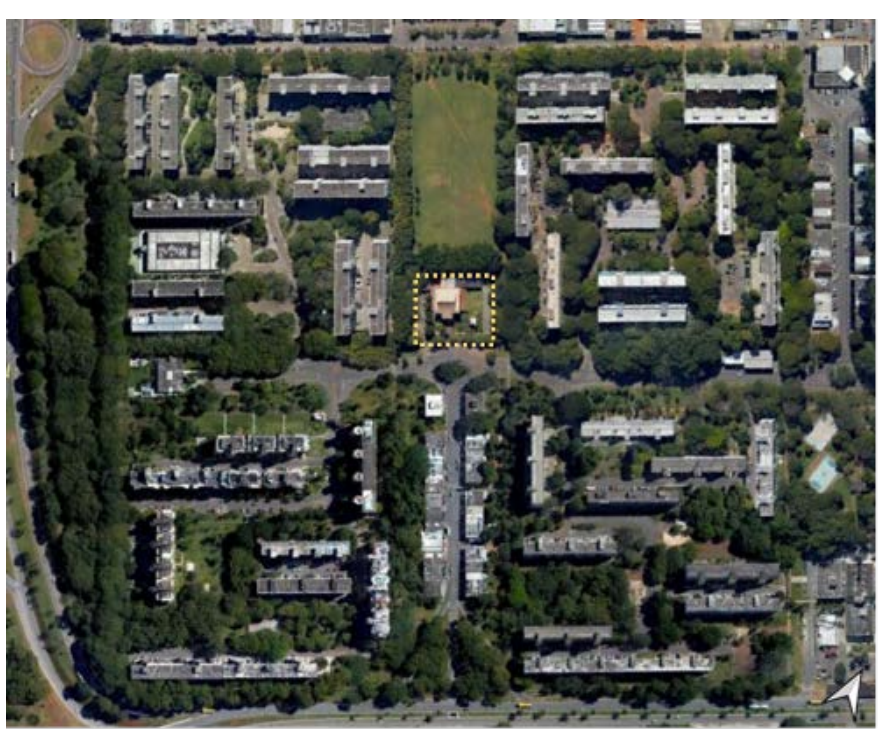

Fonte: Google Earth (2020), modificado pelos autores. 
Figura 5. Localização da Igreja Cristã Maranata na Superquadra Sul 414.

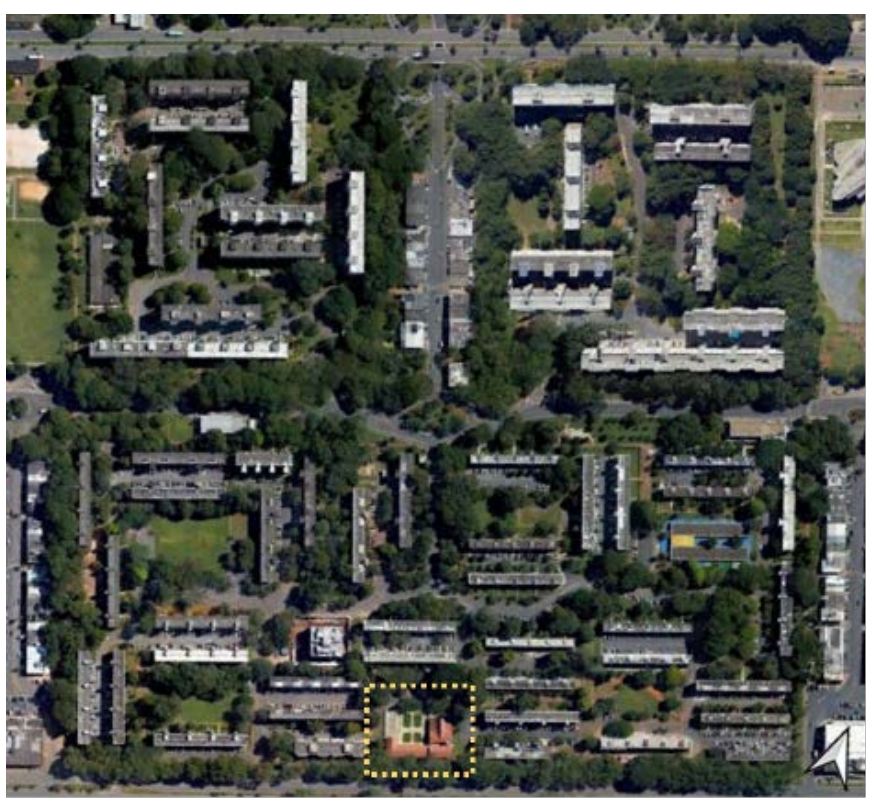

Fonte: Google Earth (2020), modificado pelos autores.

Todas as edificações encontradas, nas duas Asas consideradas, foram construídas para seu devido fim, não sendo identificado nenhum caso de adaptação para esse uso específico. Algumas poucas passaram por reformas pontuais, mantendo as características essenciais dos projetos originais.

Quanto às datas de construção, identificou-se a maior ocorrência nas décadas anteriores a 2000. A maior parte das edificações das Superquadras Sul (oitos delas) foi construída entre as décadas de 1950 e 1970 , período correspondente ao momento inicial de construção e ocupação, em geral, das quadras nessa porção da cidade. Nas décadas seguintes, 1980 e 1990, apenas duas edificações religiosas foram construídas. As demais não tiveram suas datas identificadas. Já nas Superquadras Norte, a maior parte delas (considerando as datas reconhecidas) foi construída já na década de 1990, o que pode estar relacionado à ocupação mais tardia da Asa Norte, quando comparada com a ocupação da Asa Sul.

As edificações catalogadas são predominantemente vinculadas ao cristianismo, dividindo-se em correntes distintas, sendo atualmente as de orientação protestante em maioria. Há, no entanto, representantes do budismo; um templo de filosofia japonesa; uma loja maçônica; um centro espírita e um centro cultural judaico. O reconhecimento das doutrinas é relevante no sentido de dar indícios para a análise da linguagem arquitetônica utilizada por cada uma.

A implantação e a altura das edificações partem dos parâmetros do Código de Obras e Edificações de Brasília, de 1967, que ditava normas edilícias para todos os setores da cidade, embora nem todas o respeitem rigorosamente. Este define, para os loteamentos destinados ao uso religioso no interior das Superquadras, o afastamento mínimo obrigatório de 20 metros e altura máxima, a partir da cota de soleira, de 12 metros. No caso dos lotes localizados no interior das superquadras duplas (termo utilizado no documento e interpretado aqui como entrequadras), a taxa de ocupação é de $100 \%$ e a altura máxima permitida é de 8 metros. O respeito à altura máxima permitida se dá em todos os casos, não havendo interferência, portanto, no gabarito uniforme proposto para as superquadras em conjunto. Destaca-se um caso específico, que é a implantação da Associação Cultural Israelita, localizada na Entrequadra 305/306 Norte, sendo a única construída abaixo do nível da rua.

No que diz respeito à autoria dos projetos, grande parte não foi identificada, tanto em pesquisa à bibliografia e à documentação levantada, quanto em entrevistas feitas com os responsáveis de cada instituição. No entanto, destacam-se entre as identificadas, obras projetadas por nomes reconhecidos nacionalmente, como Glauco Campello e Oscar Niemeyer (esse último, no já citado caso da Igreja Nossa Senhora de Fátima). Niemeyer é autor dos principais monumentos da cidade e seus projetos em Brasília fizeram parte de um esforço de produção de uma arquitetura que representasse a imagem dela como cidade moderna e desprendida do passado. Ainda quanto às autorias, outra constatação chamou atenção durante o levantamento: apenas duas das edificações, localizadas na Asa Norte, foram projetadas por mulheres 
arquitetas. São elas: a Igreja Nova Vida de Brasília (1996), de autoria de Maria Emilia L. Yamada, e a Capela da Divina Misericórdia (2007), projetada por Elídia Maria Torres. Tal informação dá indícios da atuação feminina mais presente nas produções arquitetônicas mais recentes.

\section{Análises}

Quanto às formas e às linguagens utilizadas, nota-se uma grande variação entre as edificações levantadas, embora se possam apontar também algumas convergências. Tais características resultam tanto das "tendências" arquitetônicas das diferentes décadas e afiliações dos arquitetos responsáveis, como pelos valores e concepções das doutrinas representadas pelas edificações.

Nesse sentido, percebeu-se que as igrejas de orientação cristã protestante possuem, de modo recorrente, volumes menos elaborados, geralmente prismáticos, com poucos elementos arquitetônicos em destaque. A forma prismática é, possivelmente, derivada do programa, baseado em salão principal, onde acontecem os cultos, e salas de apoio. As fachadas são definidas por superfícies lisas, interrompidas apenas pelas esquadrias e demais elementos funcionais, como brise soleil. Nelas incluem-se poucos símbolos religiosos, constando, mais expressivamente, a identificação da igreja por letreiros. Essa é uma das principais diferenças com relação às igrejas católicas, nas quais se identifica necessariamente o símbolo da cruz e a presença de torres sineiras.

São exemplos das igrejas protestantes descritas: a Igreja Cristã Evangélica de Brasília e a Igreja Batista Capital (Figuras 6 e 7). A primeira está localizada na Entrequadra 110/109 Norte, em frente às quadras comerciais, em posição central na via transversal à quadra, constituindo-se ponto focal para quem ali circula. Consiste em uma construção de forma simples, tendo a marquise atirantada como único elemento de destaque. De modo semelhante, a Igreja Batista Capital está localizada na Entrequadra 407/408 Norte, protegida por grades e rodeada por árvores, sem se destacar-se com relação ao entorno. Essa edificação possui ainda menos elementos arquitetônicos evidentes, destacando-se apenas o letreiro em sua fachada.

Figura 6. Igreja Cristã Evangélica de Brasília (de 1981)

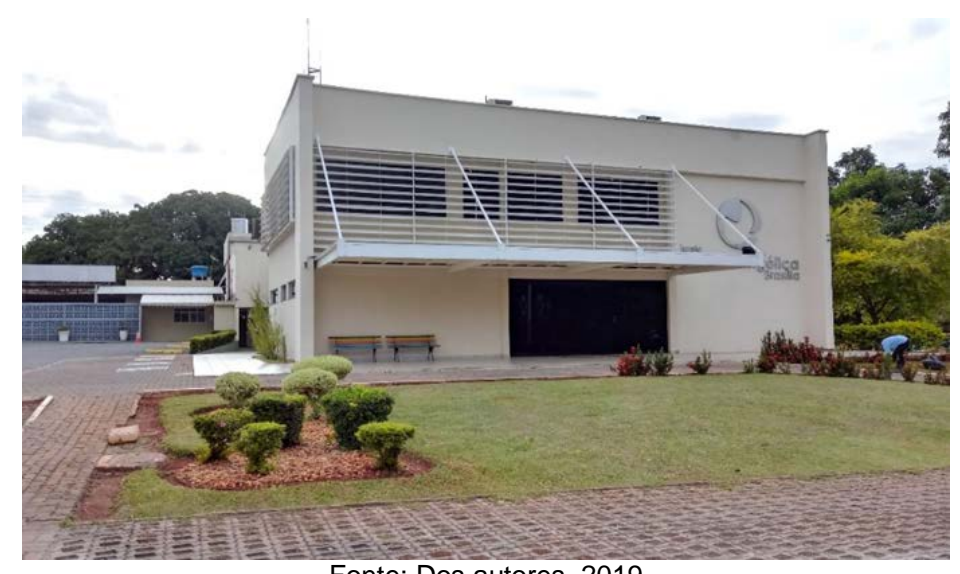

Fonte: Dos autores. 2019

Figura 7. Igreja Batista Capital (da década de 1990, sem data específica)

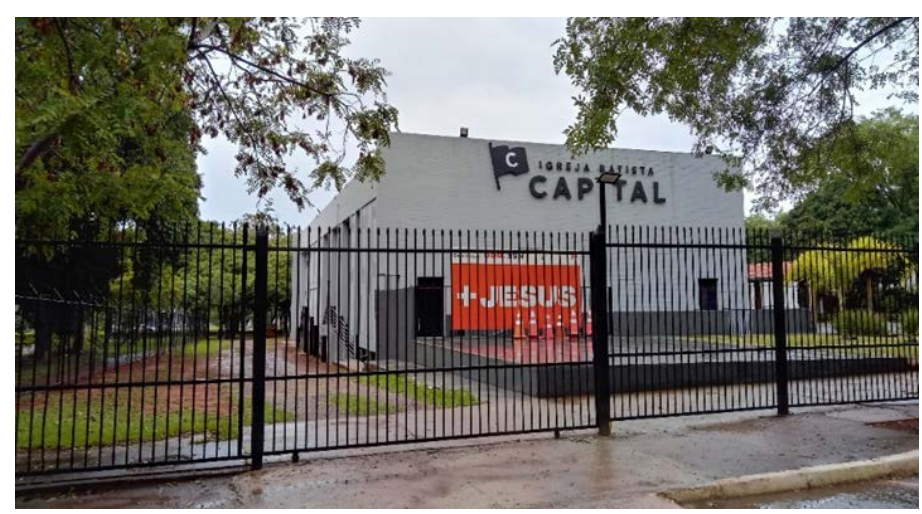


Em contrapartida, os templos de filosofia e doutrina oriental, em geral, apresentam formas que evidenciam mais nitidamente suas origens. O Templo Shin Budista Terra Pura (Figura 8), por exemplo, foi construído ao estilo do pagode japonês, tendo como referência o templo Shin Budista Reisenji na província de Fukui, no Japão, construído entre 1336 e 1573 no período Muromachi. Os templos japoneses desse estilo são inspirados em modelos xintoístas, onde cada elemento arquitetônico, como as janelas, telhados, pórticos e a até a decoração interna da nave buscam modelos em estilos tradicionais diversos, sendo caracterizados por seu ecletismo. Essa edificação foi projetada no Japão, no final dos anos 1950, e adaptada às normas de edificação e gabarito locais pelo arquiteto brasileiro Jihei Noda, de ascendência japonesa, para obter o alvará de construção fornecido pela Administração de Brasília (informações retiradas do Memorial Descritivo de Tombamento, de 2015).

Figura 8. Tempo Shin Budista Terra Pura (de 1964)

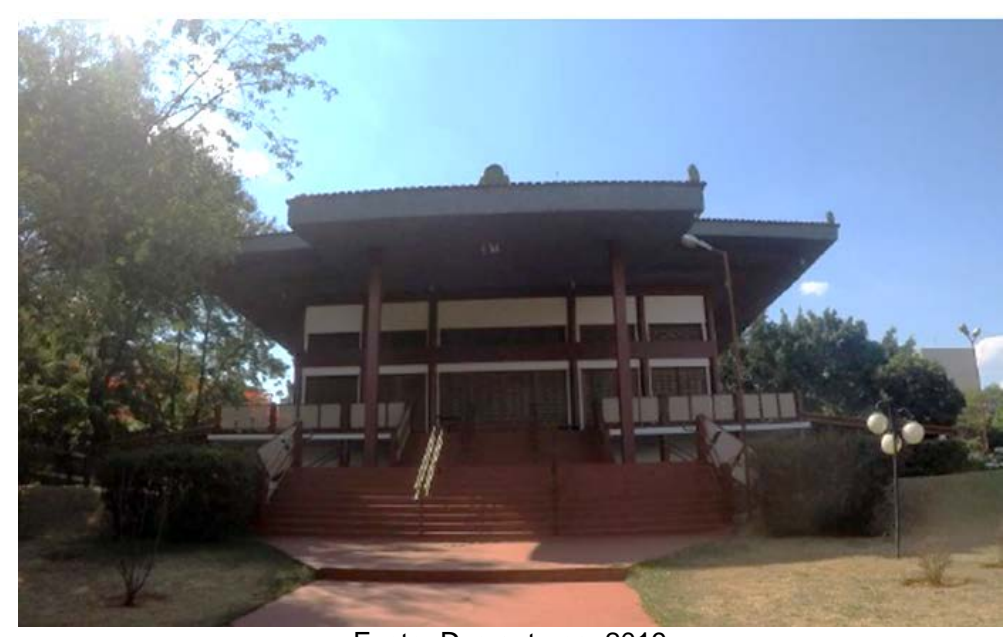

Fonte: Dos autores. 2019

Apesar de não se mostrar tão evidente, a presença "estrangeira" também se dá no projeto da Paróquia Nossa Senhora de Guadalupe (Figura 9), dedicada à Virgem de Guadalupe, padroeira das Américas, que segundo consta no site da própria instituição, teria aparecido pela primeira vez no México, em 9 de dezembro de 1531, ao índio Juan Diego (PAROQUIA DE GUADALUPE, s/d). O edifício foi projetado pelo arquiteto brasileiro Vicente de Paulo Lima, juntamente com o arquiteto mexicano Francisco Salgado conforme depoimento de Lima $^{7}$, na época da construção este último era o encarregado de projetos da Congregação dos Legionários de Cristo. Destacam-se, como características essenciais da edificação o acesso principal elevado por escadaria e destacado pelo vitral em forma de arco romano; e a platibanda triangular, que sugere o formato do frontão clássico. Esses elementos remetem à linguagem comumente encontrada em edificações católicas apostólicas na Europa e em alguns países latino-americanos de colonização europeia, embora não constituam uma regra entre elas.

Figura 9. Paróquia Nossa Senhora de Guadalupe (de 1999)

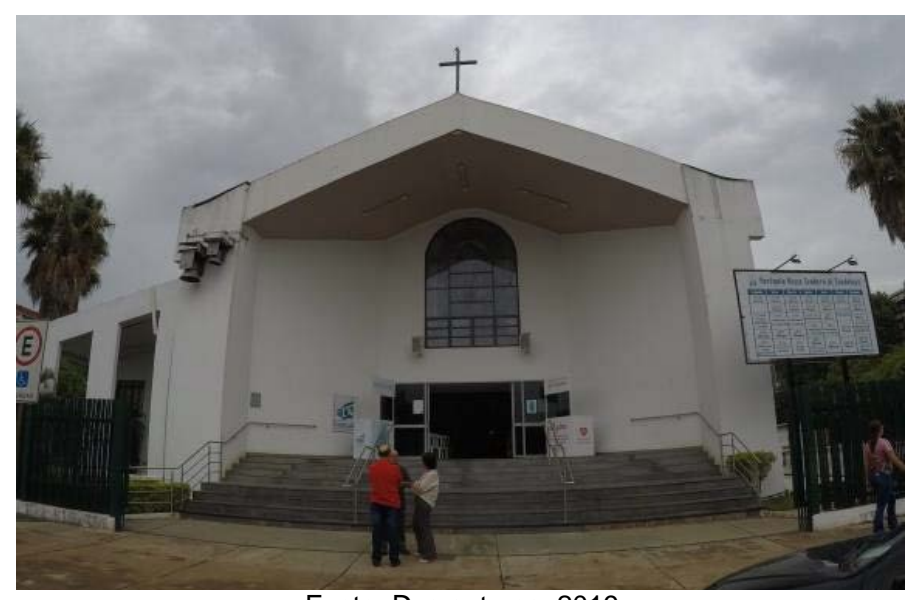

Fonte: Dos autores. 2019 
No que tange à relação com os períodos de construção, nota-se que as primeiras edificações religiosas construídas dialogam mais nitidamente com a linguagem arquitetônica modernista dos monumentos de Brasília, edificados concomitantemente (nas décadas de 1950 e 1960). Nelas se evidencia a valorização da forma geométrica pura e o uso do concreto armado pintando na cor branca. Destaca-se, ainda, o papel dos sistemas estruturais e, sobretudo, das coberturas na definição dos volumes. São exemplos: a Igreja Nossa Senhora de Fátima, de Oscar Niemeyer; a Igreja Episcopal Anglicana, de Glauco Campello; e a Igreja Evangélica de Confissão Luterana de Brasília, de Del Nero (Figura 10).

Figura 10. Igreja Nossa Senhora de Fátima (de 1958), Igreja Episcopal Anglicana (de 1960) e Igreja Evangélica de Confissão Luterana de Brasília (de 1969), da esquerda para a direita

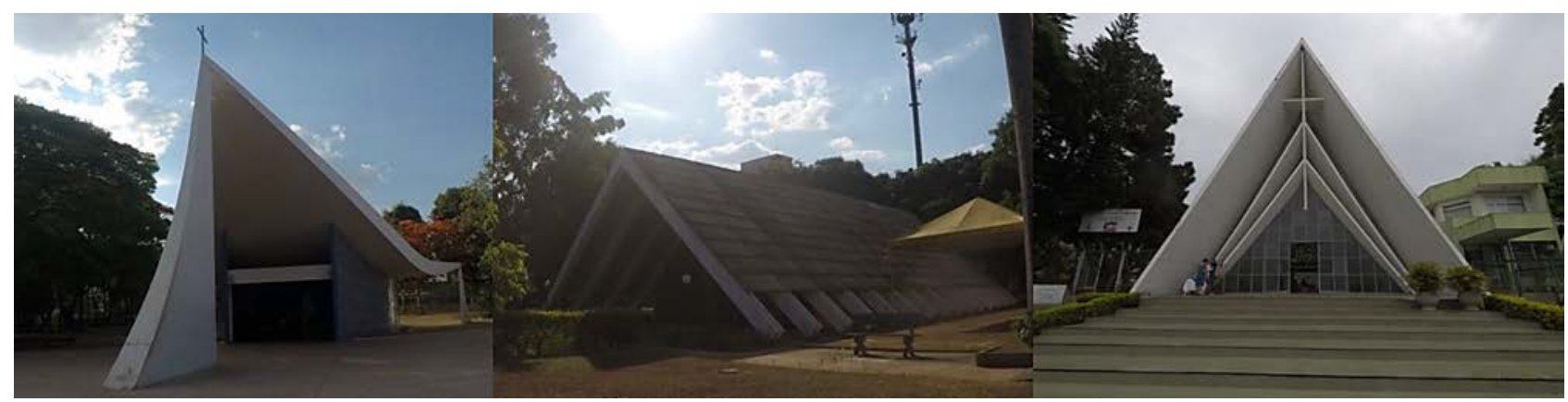

Fonte: Dos autores. 2019

No diálogo com a arquitetura de Brasília, vale também apontar dois casos específicos em que, embora o volume geral e as fachadas em muito se distanciem da linguagem desta, encontram-se elementos que se assemelham, ainda que sutilmente, às formas icônicas presentes nos palácios do governo. Trata-se da Igreja Presbiteriana da Alvorada e da Igreja Nova Vida de Brasília (Figuras 11 e 12). A primeira, embora não se localize centralizada na Entrequadra, tem sua fachada frontal em destaque na via principal de acesso da área residencial da Superquadra (410 Norte). Centralizado, o pórtico de sua fachada frontal, cujo formato se assemelha aos pilares do Palácio da Alvorada, é facilmente notado, juntamente com as rampas de acesso e ao jogo de cores trabalhado nos vidros.

Figura 11. Igreja Presbiteriana da Alvorada (de 1968)

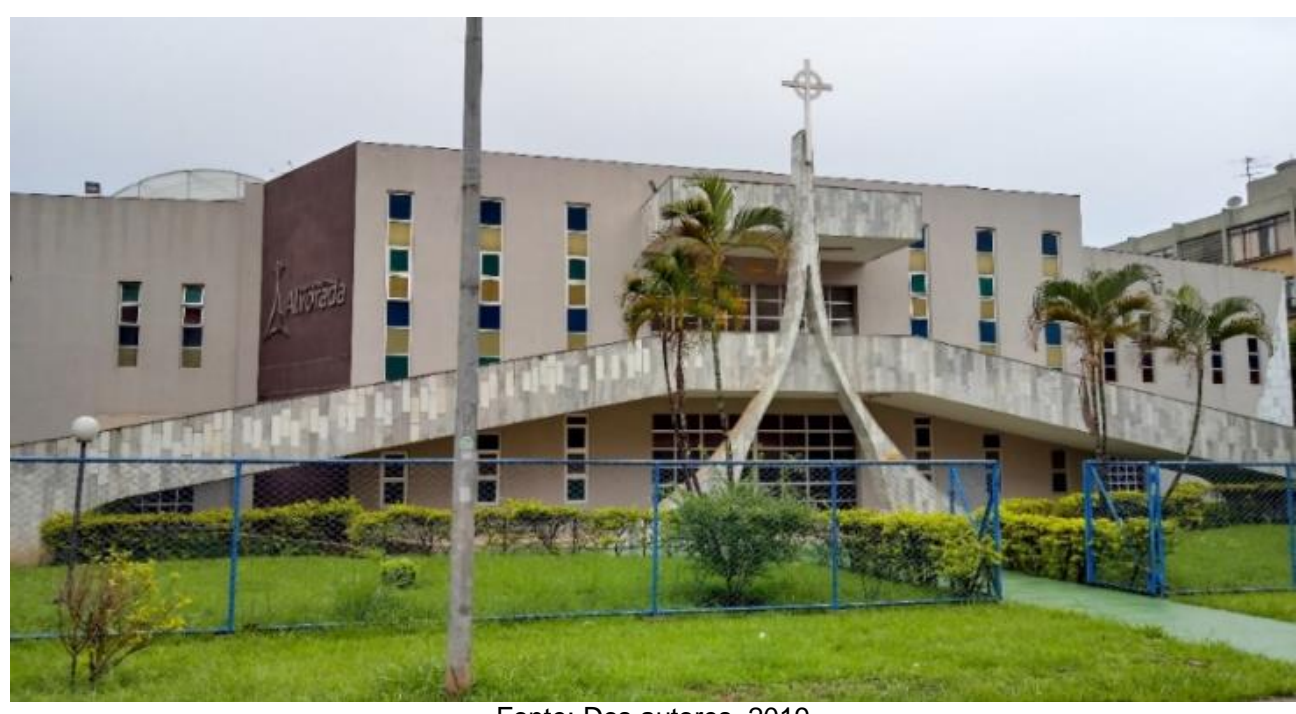

Fonte: Dos autores. 2019

Na Igreja Nova Vida de Brasília, localizada na entrada da área residencial da Superquadra (412 Norte), destaca-se o elemento central, definido pelo encontro das duas frações da marquise na fachada frontal, marcando o acesso principal ao templo, com forma curva, também semelhante àquelas já mencionadas dos palácios governamentais, ou mesmo remetendo à imagem de duas mãos em oração. Em ambas as igrejas citadas, os elementos da fachada assumem o papel ornamental e plástico, sobrepondo-se aos volumes prismáticos simples das edificações. 
Figura 12. Igreja Nova Vida de Brasília (de 1996)

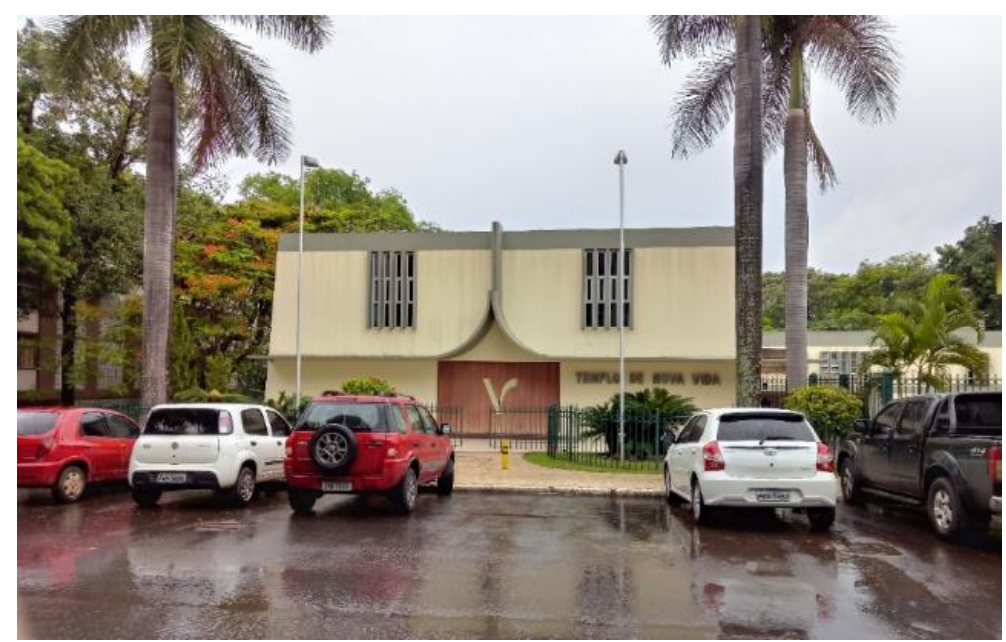

Fonte: Dos autores. 2019

Nas edificações construídas entre 1970 e 1990 identifica-se a maior ocorrência de símbolos e elementos da história da arquitetura anexados às fachadas. Tal atributo decorre das já citadas referências das próprias doutrinas, mas também pode ser associado ao período em que foram construídas. É justamente nessas décadas que se desenvolve mais expressivamente a linguagem arquitetônica pós-modernista no país. Conforme aponta Otília Arantes, esse estilo valoriza a ornamentação e o uso de formas e composições históricas, os quais aludem (de modo direto ou indireto) aos grandes símbolos da arquitetura (ARANTES, 2000).

Nesta condição, o caso mais evidente é o da Loja Maçônica Grande Oriente do Distrito Federal (Figura 13), datada de 1971, e localizada dentro da 416 Norte. A edificação apresenta símbolos, tanto da própria ordem quanto referências a elementos da cultura egípcia, com estátuas que seguem a estilização de tal cultura, além do uso de mármore colorido.

Figura 13: Loja Maçônica Grande Oriente do Distrito Federal (de 1971)

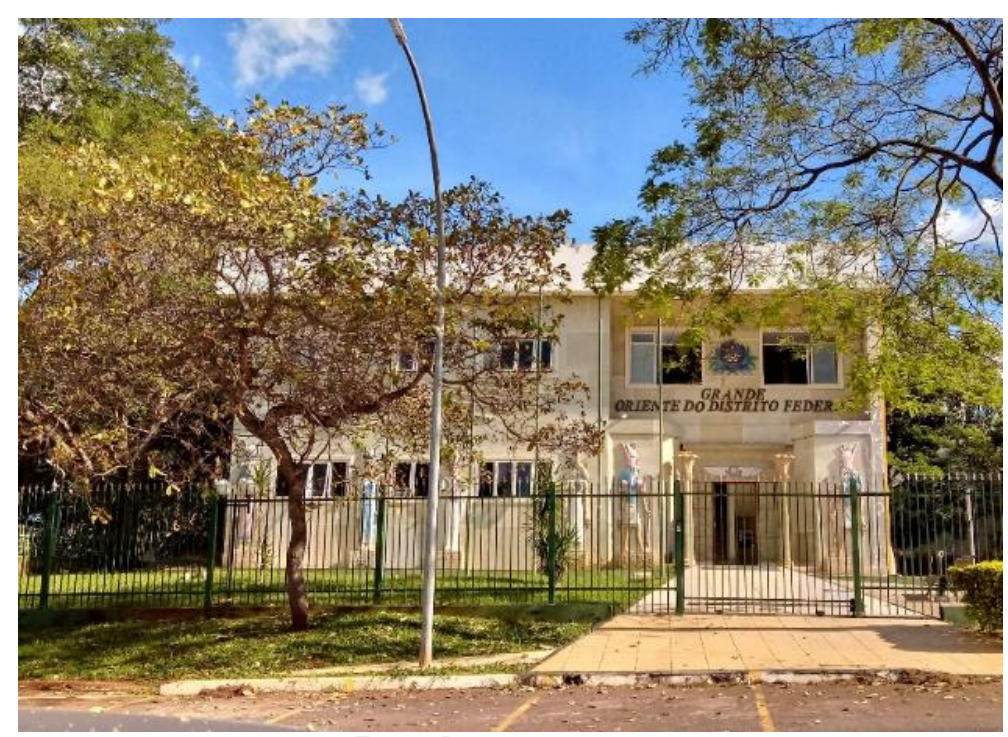

Fonte: Dos autores. 2019

Já a Paróquia Nossa Senhora da Esperança (Figura 14), na Entrequadra 308/307 Norte, traz os símbolos arranjados de maneira menos notória, gerando, através de formas geométricas, a representação do cálice sagrado. A composição resultante da combinação de formas puras e cores na sua fachada remete mais especificamente à linguagem pós-moderna explorada por arquitetos norte-americanos, como Michael Graves $(1934-2015)^{9}$. Aqui, as formas dos elementos presentes na fachada assumem o papel de indicar a 
função à qual se destina o edifício, ainda que explorando os recursos geométricos com maior peso do que os icônicos, sem recorrer ao uso de letreiros.

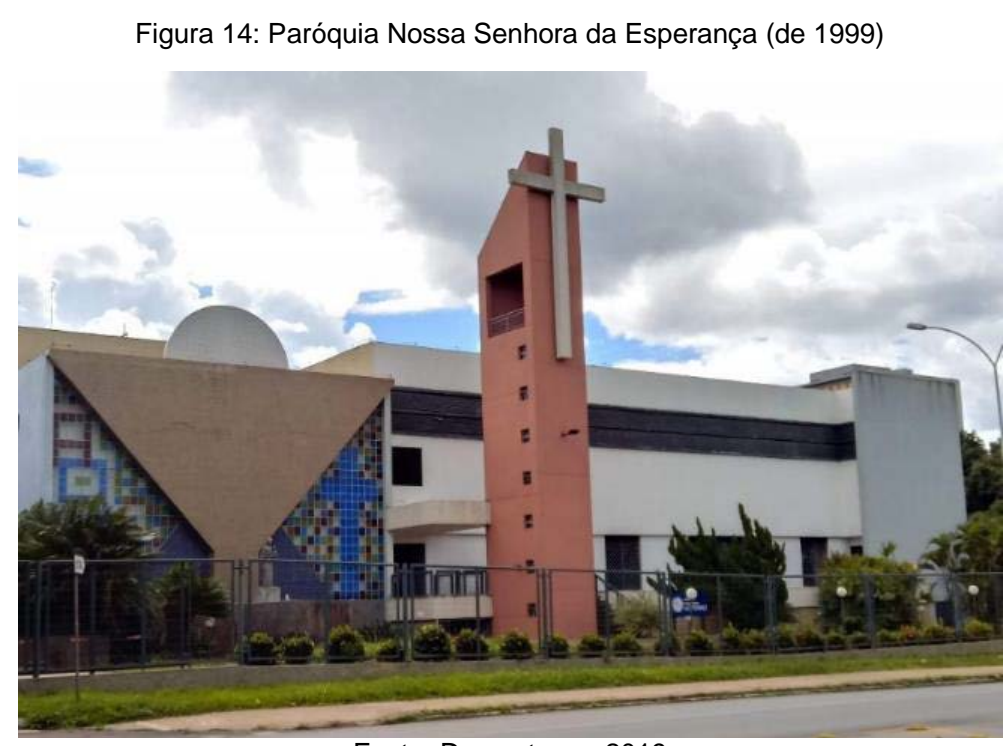

Fonte: Dos autores. 2019

Por fim, as edificações construídas mais recentemente apresentam características formais variadas, em termos de estilos e referências, sem que se possa, portanto, categorizá-las por propriedades temporais únicas. Entre aquelas que tiveram suas datas identificadas, a mais recente é a Capela da Divina Misericórdia (Figura 15), de 2007. Seu atributo formal mais evidente é a presença da arcada em sua fachada - uma sequência de arcos romanos, de volta perfeita -, em uma clara alusão à arquitetura tradicional, constituindo um tipo de 'nártex' (zona de entrada do templo). No entanto, tais características são combinadas com formas simples, sem ornamentações e em escala modesta, não indicando, portanto, qualquer compromisso estilístico.

Figura 15: Capela da Divina Misericórdia (de 2007)

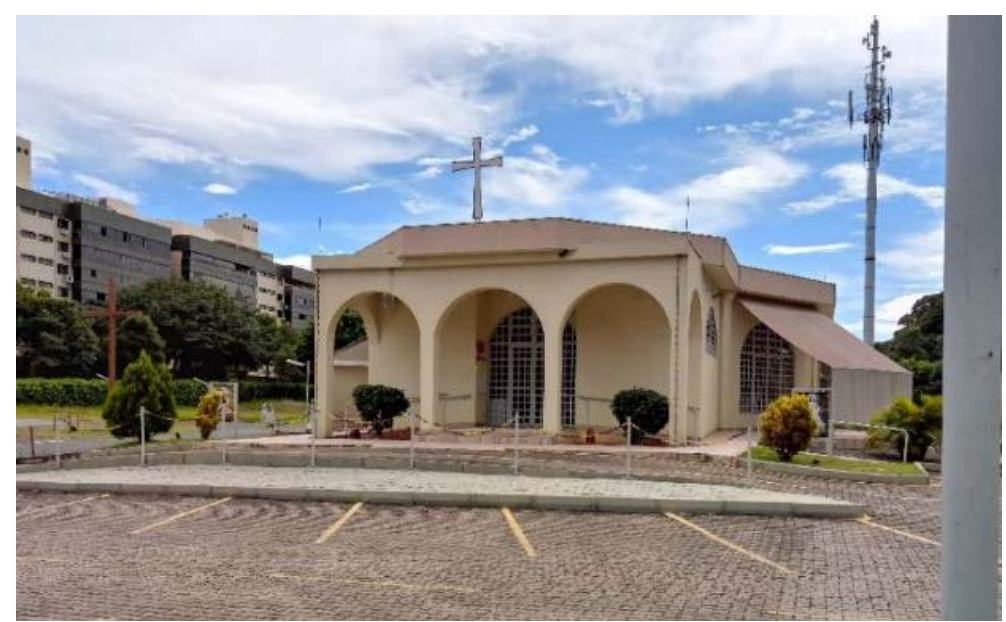

Fonte: Dos autores. 2019

Este último caso é representativo de uma tendência identificada nas edificações mais recentes em Brasília, de desprendimento do compromisso com a linguagem modernista ou mesmo do enquadramento em vertentes arquitetônicas, que podem ser reconhecidas em obras anteriores. 


\title{
3 CONCLUSÃO
}

O levantamento realizado teve parte de seus objetivos cumpridos, tendo em vista os acessos limitados às informações buscadas. Porém, é possível afirmar que a pesquisa trouxe à tona dados pouco divulgados, incentivando uma compreensão mais profunda dos edifícios religiosos encontrados nos setores residenciais de Brasília. O estudo propiciou, ainda, um contato enriquecedor com o vocabulário da arquitetura religiosa. Diante do que foi levantado, puderam-se constatar distinções e características comuns quanto às doutrinas, estilos arquitetônicos adotados e períodos de construção dessas edificações.

O diálogo com o conjunto arquitetônico de Brasília se dá de forma mais evidente nos projetos iniciais, que seguem as referências do modernismo próprio da arquitetura inaugural da cidade, tendo, em alguns casos, inclusive, os mesmos arquitetos como autores. A partir dos resultados preliminares dessa pesquisa, entende-se, aqui, que essas edificações iniciais, além de bem inseridas no contexto das superquadras, possuem valor plástico mais evidente, com volumes que exploram a forma e as concepções estruturais de maneira habilidosa, sem, no entanto, quebrar as expectativas citadas da sobriedade formal. $\mathrm{O}$ que se percebe com o avançar do tempo, é que, em grande medida, o cuidado com a expressividade plástica das edificações religiosas diminuiu e que, nessas edificações, os símbolos religiosos e elementos "anexos" às fachadas, assumiram um papel de identificação e ornamentação, que se sobrepõe a essa qualidade. No entanto, apesar disso e, embora se reconheçam linguagens muito distintas, nota-se que há, ainda, certo respeito ao conjunto e à concepção urbanística da cidade pela necessidade da obediência (parcialmente respeitada) aos parâmetros urbanísticos estabelecidos para seus lotes.

Vale lembrar, ainda, que o recorte espacial estabelecido não abrange todas as manifestações da arquitetura religiosa na cidade, não sendo possível, portanto, concluir sobre as expressões de todo o conjunto, o que de fato, não era a proposta dessa pesquisa. É certo que depois da última data de construção identificada entre as edificações levantadas (2007) foram construídas outras muitas edificações religiosas na cidade, sobretudo com a expansão das igrejas neopentecostais.

Reitera-se a conclusão do trabalho apresentado neste artigo como um ponto de partida sobre o tema, uma vez que, com base nos levantamentos e análises apontados, novas pesquisas podem ser realizadas como desdobramentos, propiciando reflexões mais profundas a respeito de cada edificação e dos tópicos a elas relacionados.

\section{REFERÊNCIAS}

\author{
ARANTES, O. B. F. O lugar da arquitetura depois dos modernos. $3^{\mathrm{a}}$ edição, São Paulo, Edusp, 2000.
}

BRASÍLIA (Distrito Federal). Decreto n. 596, de 8 de março de 1967. Código de Edificações de Brasília. Disponível em: http://www.sinj.df.gov.br/sinj/Norma/0513067258d14c489003a65d03a4998f/exec dec 596 1967.html. Acesso em: abril de 2020.

COSTA, L. Relatório do Plano Piloto de Brasília. Brasília: Iphan; Secult, 2014 [1957].

FERREIRA, M. M.; GOROVITZ, M. A invenção da superquadra. 2a edição. Brasília: Superintendência do Iphan no Distrito Federal, Instituto do Patrimônio Histórico e Artístico Nacional, 2020.

FICHER, S.; PALAZZO, P. P. Os paradigmas urbanísticos de Brasília. Salvador: Cadernos PPG-AU/UFBA, v. 4, n. 0, 2005. Disponível em: <https://rigs.ufba.br/index.php/ppgau/article/view/1693>. Acesso em: 2 maio 2021.

PAROQUIADEGUADALUPE (Padroeira). Informações e serviços da paróquia. Disponível em: https://paroquiadeguadalupe.com.br/padroeira/. Acesso em 4 abril 2020.

TEMPLO SHIN BUDISTA TERRA PURA. Memorial descritivo do tombamento. Terra Pura. [Online] 2015. Disponível em: https://www.terrapuradf.org.br/tombamentol. Acesso em: 4 abril 2020.

ROCHA, R. Por uma nova monumentalidade. O Monumento Nacional aos Mortos na Segunda Guerra Mundial no Rio de Janeiro. Arquitextos, São Paulo, ano 12, n. 136.04, Vitruvius, set. 2011. Disponível em https://vitruvius.com.br/ revistas/read/arquitextos/12.136/4040. Acesso em: 4 abril 2020.

TAVARES, J. Projetos para Brasília: 1927-1957. Brasília: IPHAN, 2014.

\section{NOTAS}

${ }^{1} \mathrm{Na}$ superquadra, os equipamentos comunitários, como as escolas, situam-se em lotes, enquanto a localização e as dimensões dos blocos residenciais são definidas por projeções (FERREIRA\&GOROVITZ, 2020).

${ }^{2}$ Companhia Urbanizadora da Novacap, responsável pela construção de Brasília. 
3 Tais fichas foram apresentadas como anexo dos trabalhos no relatório final da Iniciação Científica. Nesse artigo, porém, as informações são apresentadas de modo sintetizado.

${ }^{4}$ Entende-se, aqui, que a análise concentrada nas imagens externas das edificações é apenas o primeiro passo do levantamento e da catalogação, que encaminha às primeiras conclusões, sendo necessário um estudo mais completo dos programas e sistemas construtivos, a ser realizado em interpretações futuras, como desdobramento dessa primeira pesquisa.

${ }^{5}$ Quatro das edificações levantadas na Asa Norte não apresentam informações suficientes para subsidiar as análises.

${ }^{6}$ No Plano Piloto de Brasília, as quadras residenciais são identificadas por números, conforme sua posição com relação ao centro da cidade (onde há o encontro dos Eixos Rodoviário e Monumental).

${ }^{7}$ Em entrevista concedida a uma das autoras em 2019.

${ }^{8} \mathrm{O}$ arquiteto Glauco Campello trabalhou junto a Oscar Niemeyer na construção de Brasília, sendo responsável por outros projetos, como o Centro de Reabilitação Sara Kubitschek (primeira fase), da residência do Arcebispo de Brasília e das capelas do Cemitério Campo da Boa Esperança.

${ }^{9}$ Arquiteto americano pós-moderno, com uma de suas obras mais icônicas sendo o edifício Portland no estado de Oregon, EUA.

NOTA DO EDITOR (*): O conteúdo do artigo e as imagens nele publicadas são de responsabilidade do(s) autor(es). 